\title{
Textos que dão voltas por aí: Borges, Katchadjian, obra e autoria na literatura contemporânea
}

\author{
Rejane Cristina Rocha ${ }^{1}$
}

\begin{abstract}
O Quixote - disse-me Menard - foi antes de tudo um livro agradável; agora é uma ocasião de brindes patrióticos, de soberba gramatical, de obscenas edições de luxo. A gloria é uma incompreensão e talvez a pior.
\end{abstract}

Jorge Luis Borges

\section{O autor e a obra}

Dois textos críticos, publicados durante a década de 1960, foram de seminal importância para as reflexões subsequentes acerca das relações existentes entre o que se compreende por autor e por obra na modernidade ocidental: o ensaio "A morte do autor", de Roland Barthes, de 1968, e o livro O que é um autor?, de Michel Foucault, de 1969.

No texto de Barthes, a reflexão acerca da autoria embasa seu conceito de escritura. O autor é visto por Barthes (2004, p. 58) como uma entidade que atestaria o prestígio que a individualidade, o racionalismo e o empirismo alcançaram no seio da sociedade moderna e, justamente por ter sua origem ancorada nos pressupostos hermenêuticos da modernidade, o autor reuniria, em torno de si, os preceitos da origem e da originalidade, sustentando a concepção de texto como produto acabado, com um significado último, fechado em si. Proveniente dessa concepção que vincula a origem e a originalidade a uma fonte primeira de significados está a concepção de literatura "tiranicamente centralizada no autor, sua pessoa, sua história, seus gostos, suas paixões" (Barthes, 2004, p. 58). Tais concepções de autoria e de literatura são contestadas por Barthes, em nome do estabelecimento do conceito de escritura, cujo processo prevê a constituição do texto como "um espaço de dimensões múltiplas onde se casam e se contestam escrituras

\footnotetext{
${ }^{1}$ Doutora em Estudos Literários e professora da Universidade Federal de São Carlos (UFSCar), São Carlos, SP, Brasil. (Dorcid.org/0000-0002-5944-6846. E-mail: rjncris@gmail.com
} 
variadas, das quais nenhuma é original: o texto é um tecido de citações, oriundas dos mil focos de cultura" (Barthes, 2004, p. 62).

A reflexão proposta por Foucault (1992) também identifica o autor à consolidação da ideia de sujeito moderno, coincidente com um momento histórico da cultura ocidental de "forte individualização" (Foucault, 1992, p. 33). Para além da conhecida proposição de Foucault, a de substituir a ideia de autor como indivíduo que é fonte de significados pelo conceito de função autor, "característica do modo de existência, de circulação e de funcionamento de alguns discursos no interior de uma sociedade" (Foucault, 1992, p. 46), interessa-me sobremaneira, para a argumentação que pretendo desenvolver, a inextricável relação que o filósofo estabelece entre obra e autor.

Ao denunciar, em seu livro, a ausência de reflexão em torno do conceito de obra, Foucault enfeixa algumas questões ainda hoje muito pertinentes:

O que é uma obra? Em que consiste essa curiosa unidade que designamos por obra? Que elementos a compõem? Uma obra não é o que escreveu aquele que se designa por autor? Se um sujeito não é um autor o que ele escreve pode ser considerado uma obra? Tudo o que escreve um autor pode ser considerado parte de sua obra? (Foucault, 1992, p. 37-38).

As questões propostas pelo filósofo apontam para a maneira como a modernidade ocidental lida com o conceito de obra como o resultado do trabalho de um autor, sem, contudo, problematizar o fato de que não poderia existir autor sem que houvesse uma obra. É a partir dessas considerações que Foucault (1992), então, discute as especificidades do nome de autor, que não constitui - assim como Barthes (2004) também percebeu - um nome próprio como os outros, mas que "serve para caracterizar um certo modo de ser do discurso" que o resgata da banalidade dos discursos quotidianos, fundando e exigindo, para ele, um espaço de legitimidade e certo estatuto (Foucault, 1992, p. 45), um estatuto que consolida a ideia de obra.

Para Foucault (1992, p. 68), a compreensão do funcionamento da função autor levaria a um questionamento a respeito das "modalidades de existência" dos discursos, ou seja, os modos como eles circulam, são apropriados, e como a eles se atribui valor, evidenciando como tais movimentos "variam com cada cultura e modificam-se no interior de cada uma" (1992, p. 69). 
Bem mais recentemente, o historiador da cultura Roger Chartier (2012) retoma a discussão de Foucault, se não para rechaçá-la, para ampliá-la a partir de uma perspectiva proveniente das descobertas historiográficas a que Foucault não teria tido acesso quando da elaboração do seu texto, na década de 1960:

reconhecer, contrariamente ao que ele [Foucault] podia pensar, que não é tanto em função de uma aplicação particular da propriedade burguesa que nasce uma definição da propriedade literária, mas, ao contrário, se esta propriedade literária é uma das formas fundamentais de sustentação da construção de uma função autor [...] é no interior da defesa do direito do livreiro editor, e não do autor, que ela se afirma (Chartier, 2012, p. 42)

O que me interessa da argumentação de Chartier (2012, p. 50), que retoma a história do copyright, no século XVIII, para argumentar que a invenção do autor proprietário (e da propriedade literária) consolida a função-autor, é a sua conclusão de que a desmaterialização da obra literária, ou seja, sua apreensão em termos exclusivamente de "categorias estéticas ou intelectuais, independentemente das formas materiais sucessivas ou simultâneas que lhes foram dadas", adveio de um arranjo econômico-judicial para garantir os antigos privilégios dos livreiros. A proposta de Chartier pode ser compreendida, então, como uma resposta aos anseios de Foucault, relativos aos modos como determinados discursos são valorizados e legitimados, recebendo um "nome de autor", em detrimento de outros, que não recebem tal chancela. Essa resposta é formulada a partir de uma perspectiva que diz respeito à história material do livro e dos processos de edição e evidencia a maneira como um discurso, por exemplo, o literário, recebe tal designação como resultado da articulação de um complexo conjunto de fatores e de uma quantidade significativa de atores que nem de longe podem ser resumidos à figura do autor, seu talento individual, seu gênio, sua história pessoal.

Mesmo considerando como incontornáveis as reflexões de Barthes, Foucault e, mesmo, Chartier - embora a abordagem que proponho seja tributária de algumas de suas propostas - para a discussão a respeito do surgimento e estabelecimento da ideia de autor tal qual ela se consolidou na modernidade ocidental, gostaria de seguir um outro caminho. Não um caminho que rechace ou descure dos conceitos e argumentos desses autores, mas que os 
coloque como pontos de partida de um percurso que almeja a discussão do tempo presente, da contemporaneidade. Isso porque, muito embora as proposições seminais desses autores continuem sendo importantes marcos teóricos e conceituais sobre a questão, percebo que as discussões relativas à autoria, à originalidade e ao conceito de obra, na contemporaneidade, apontam na direção de algumas especificidades que Barthes e Foucault, principalmente, não tinham como prever. A tecnologia digital e tudo o que ela possibilita em termos de barateamento dos processos editoriais e de reprodutibilidade, da ampliação da circulação dos textos e da facilidade das apropriações e reapropriações (NuNberg, 1993) coloca-nos, hoje, em um contexto muito diferente daquele em que os autores franceses se encontravam quando um preconizou a morte do autor em benefício da escritura e, outro, se questionou sobre o seu estatuto na modernidade ocidental.

Atento a esse contexto contemporâneo específico, este artigo não examina uma obra - este conceito também tão rasurado em seus alicerces, na contemporaneidade -, mas um caso que, ao mesmo tempo que glosa as reflexões basilares acerca do conceito de autoria, as coloca à prova, exigindo do analista flexibilidade suficiente para perceber que os conceitos são "teorias em miniatura", úteis sempre que estivermos dispostos a revisar sua produtividade e a admitir o seu desgaste" (Bal apud Canclini, 2012, p. 122).

A proposta deste artigo, então, é refletir como a circulação da literatura, para além dos seus espaços materiais e simbólicos ditos canônicos - o livro e a crítica literária acadêmica -, coloca em questão os conceitos e a metalinguagem que se consolidaram paralelamente à consolidação da literatura como instituição (Zumthor, 1987). Meu escopo, embora modesto, já que se dedica a discutir um único caso, é revelador dos circuitos contemporâneos da literatura e deve servir para propor um viés de análise que, quiçá, pode ser especializado e ampliado na abordagem de outros casos.

\section{Borges e Pierre Menard}

Em 1939, Jorge Luis Borges publicou, na revista Sur, pela primeira vez, seu conto "Pierre Menard, autor de Quixote". Nele, o escritor 
argentino forja uma empolada e questionável ${ }^{2}$ voz crítica, cujo objetivo é trazer à luz a obra "subterrânea", "interminavelmente heroica", "ímpar" e "inconclusa" de Pierre Menard, os "capítulos nono e trigésimo oitavo da primeira parte de Dom Quixote e de um fragmento do capítulo vinte e dois" (Borges, 1972, p. 50-51). A voz que narra, em tom de resenha, esclarece ainda que o autor:

Não queria compor outro Quixote - o que é fácil - mas o Quixote. Inútil acrescer que nunca visionou qualquer transcrição mecânica do original; não se propunha copiá-lo. Sua admirável ambição era produzir páginas que coincidissem - palavra por palavra e linha por linha - com as de Miguel de Cervantes (Borges, 1972, p. 51-52).

E o conto assim continua, em defesa da empreitada de Pierre Menard, expondo o modo metódico, sério e absolutamente racional com que o personagem teria enfrentado também de modo metódico e sério a sua absolutamente irracional ambição: escrever o Quixote. Isso poderia significar, então, tornar-se autor ao perseguir a diluição da sua própria voz autoral, a rasura de qualquer traço de originalidade, o aniquilamento da própria individualidade, "ser Miguel de Cervantes" (Borges, 1972 p. 52). No entanto, ainda não é isso o que deseja Pierre Menard, que almeja, outrossim, "continuar sendo Pierre Menard e chegar ao Quixote através das experiências de Pierre Menard".

Muito já se escreveu a respeito desse conto de Borges, e é inegável que ele se trata de um exemplo paradigmático do que Beatriz Sarlo (2008) chamou de mise en forme borgiano, uma originalidade que advém de um estar em las orillas: entre o cosmopolitismo ilustrado europeu e as injunções temático-sociais da América Latina e, especificamente, do Rio da Prata, mas também entre o escritor e o crítico, entre o contista e o filósofo. É assim que o escritor argentino "discute obliquamente os tópicos capitais da teoria literária contemporânea [...] a teoria da intertextualidade, os limites da ilusão referencial, a relação entre conhecimento e linguagem, os dilemas da representação e da narração" (Sarlo, 2008, p. 19).

\footnotetext{
${ }^{2}$ Logo no início do conto, o narrador-resenhista expõe as suas credenciais, explicitando de onde vem a sua legitimidade: foi acreditado pela Baronesa de Bacourt e pela Baronesa de Bagnoregio, cujas próprias credenciais críticas são bastante nebulosas, para não dizer inexistentes (Borges, 1972, p. 47-48).
} 
Para os limites deste artigo - que não tem o conto de Borges como seu objeto de análise senão lateralmente -, cumpre, ainda, chamar a atenção para o que é que há a distinguir os verbalmente idênticos quixotes de Cervantes e de Menard. Uma passagem do conto, ainda que extensa, dá as pistas:

Constitui uma revelação cotejar o Dom Quixote de Menard com o de Cervantes. Este, por exemplo, escreveu [...]:

...a verdade, cuja mãe é a história, êmulo do tempo, depósito das ações, testemunhas do passado, exemplo e aviso do presente, advertência do futuro.

Redigida no século XVII, redigida pelo "engenho leigo", Cervantes, essa enumeração é um mero elogio retórico da história. Menard, em compensação, escreve:

...a verdade, cuja mãe é a história, êmulo do tempo, depósito das ações, testemunhas do passado, exemplo e aviso do presente, advertência do futuro.

A história, mãe da verdade; a ideia é espantosa. Menard, contemporâneo de William James, não define a história como uma indagação da realidade, mas como sua origem. A verdade histórica, para ele, não é o que sucedeu. As cláusulas finais [...] são descaradamente pragmáticas (Borges, 1972, p. 56).

O narrador que constrói a muito ciosa crítica da irracional tarefa de Menard não conclui, mas a citação é indubitável: o empenho de Menard em escrever o Quixote idêntico ao de Cervantes e, ainda assim, estar certo de que não o copia, simplesmente, advém do pressuposto de que entre o Quixote de Cervantes e o seu próprio Quixote opera a mediação do leitor (e Menard é, antes de tudo, leitor) que impregna os textos que lê de significados que colheu de outros textos que leu. Ao leitor contemporâneo, que leu os pós-estruturalistas, a passagem transcrita certamente reverbera os questionamentos acerca da certeza referencial e da crise da representação, bem como a proposta de Barthes ao afirmar que "é no leitor que se reúnem os significados múltiplos e dispersos de que se constitui a escritura, o texto, não no autor" (Barthes, 2004, p. 64). Ou seja, para o leitor contemporâneo, Borges anteviu as principais discussões acerca dos conceitos de autor e de autoria que animariam as reflexões de Barthes e Foucault, décadas depois. Ou seria a leitura de Barthes e Foucault que modela as interpretações contemporâneas 
do conto de Borges? A questão, assim colocada, nos leva de volta a Borges, ao seu texto de 1952, "Kafka y sus precursores":

O poema Fears and scruples, de Robert Browling, profetiza a obra de Kafka, mas a leitura que fazemos de Kafka aguça e desvia sensivelmente nossa leitura do poema. Browning não o lia como lemos agora [...]. O fato é que cada escritor cria seus precursores. Seu trabalho modifica nossa concepção do passado e também de futuro (Borges, 1974, p. 711-712, tradução nossa).

O conto "Pierre Menard, autor de Quixote", construído com a refinada ironia borgiana, já tão conhecida dos leitores e críticos, parece se fundamentar em um questionamento que traduz a angústia de qualquer escritor moderno, atormentado com a dupla exigência de inscrever-se no cânone e produzir algo original: como e o que escrever depois de Dom Quixote, Hamlet, Misses Dalloway? (e a lista poderia ser ampliada ou modificada de acordo com o paideuma de cada um, dentro do vasto domínio do cânone ocidental).

O mesmo questionamento é enfrentado por Pablo Katchadjian, que coloca "El Aleph", de Jorge Luis Borges, na enumeração anterior. É a resposta que ele dá à questão "O que escrever depois de..." e o que ela significa para a compreensão contemporânea acerca dos circuitos do literário na contemporaneidade e do conceito de autor que me interessa discutir a partir deste ponto.

\section{El aleph engordado}

Em 2009, Pablo Katchajian ${ }^{3}$ lança por seu selo independente, Imprenta Argentina de Poesía, com uma tiragem bastante exígua, ${ }^{4}$ o livro El aleph engordado. Essa obra, segundo o autor, seria a segunda a integrar uma trilogia da qual fariam parte Martin Fierro ordenado alfabeticamente, publicado em 2007, e um terceiro livro,

\footnotetext{
${ }^{3}$ Alguns resenhistas (Reis, s.d.; Aira, 2009/2010) designam Pablo Katchadjian como um escritor de vanguarda, pelas obras que tem publicado. Além das mencionadas, o autor publicou, ainda: Qué hacer, em 2010, Gracias, em 2011, La cadena del desánimo, em 2012, La libertad total, em 2013; a uni-las, uma sem-cerimônia com as formas narrativas tradicionais, que são frequentemente colocadas em questão nas suas obras. Antes, tinha publicado dois livros de poesia: Dp canta el alma, em 2004, e Los albañiles, de 2005.

${ }^{4}$ A quantidade exata é imprecisa: o próprio autor e resenhistas da obra afirmam terem sido impressos entre 150 e 300 livros. Tivemos acesso à versão em PDF disponibilizada na página do Facebook "Apoyo a Pablo Katchadjian”.
} 
ainda não lançado, mas que, especula-se (Aira, 2009), teria El matadero como ponto de partida.

El aleph engordado consiste, então, de obra que parte do conto El aleph, de Jorge Luis Borges, publicado pela primeira vez na revista Sur, em 1945. Ao conto de Borges, composto por 4.000 palavras, Pablo Katchadjian acrescentou 5.600 palavras. De acordo com o autor:

E foi muito trabalhoso, porque eu queria permanecer em uma posição intermediária ao engordar: não ser eu nem ser Borges, isto é, não perdê-lo nem me perder. Sim, eu poderia deslizar às vezes mais para um ou outro lado, mas sem chegar a ser paródico - porque eu não queria isso - nem, digamos, hostil e agressivo - uma vez que o texto estava me recebendo, eu tinha de ser gentil (Katchadjian, s.d.).

O depoimento do autor faz ecoar o conto "Pierre Menard, autor de Quixote", que poderia ser lido como o direcionamento metodológico de Katchadjian nesse experimento literário, enquanto o conto engordado daria a sua justificativa conceitual, uma vez que, no conto de 1945, trata-se, entre outras muitas possibilidades de interpretação, de problematizar a possibilidade de expansão infinita do universo, a partir de um único ponto.

Seria necessário fazer um esforço, nesse ponto, para descrever o que há de comum no processo de execução da trilogia incompleta, sem que, de antemão, se qualificasse o procedimento. Mas, como descrever o processo sem, de saída, usar termos teóricos e conceituais que já cumprem a tarefa de qualificar, dada a sua longa trajetória conceitual? Intertextualidade, paródia, pastiche, apropriação, ressignificação... empregar qualquer desses conceitos na descrição do trabalho de Pablo Katchadjian é filiar-se a uma corrente teórica, além de admitir um juízo de valor que antecede o próprio exame da obra. Mas isso é incontornável e, de certa forma, é desejável, parece-me, uma vez que a trilogia de Katchadjian não apenas elege obras anteriores a fim de, a partir delas, criar suas obras, como também coloca em questão uma hierarquização entre o "original" e tudo o que dele advém - o Martin Fierro e sua reordenação, El aleph e sua ampliação, El matadero e seja lá o que for que com ele será feito -, que assombra todos esses conceitos e aquele que, julgamos, está na base de todos eles, que é o conceito de autoria. Assim, em lugar da recusa 
em usar tais conceitos para a caracterização da trilogia do escritor argentino, há que se aceitar a provocação e os questionar.

Como disse em outro momento, interessa, para este artigo, o segundo volume do que virá a ser a trilogia: El aleph engordado. A escolha se justifica porque o que interessa aqui não é uma análise formalista das relações entre o texto "original", de Borges, e o "derivado", de Katchadjian, mas, sim, a apreciação do movimento em que se coloca o literário e os conceitos que o sustentam, sobretudo os de autor e de autoria, a partir do momento em que o escritor argentino, ao enfrentar a questão "como recomeçar para além de um patrimônio estabelecido?", enfrenta a própria noção de patrimônio e, enfim, responde de maneira muito borgiana à questão: "como fazer literatura depois de Borges?" (Canclini, 2012, p. 125).

Em seu livro A sociedade sem relato, Canclini (2012) expõe, ao mesmo tempo em que rasura, a clássica distinção entre arte (bens apreciados pelo seu valor estético) e patrimônio (bens apreciados pelo seu valor histórico). Analisando casos e obras, o autor demonstra como essa distinção, que apoia as políticas culturais, as estratégias museográficas e as iniciativas de preservação, não mais responde à complexidade de um momento em que os usos econômicos, religiosos, midiáticos, turísticos, estéticos - da arte e do patrimônio se multiplicam e corroem por dentro a estabilidade da distinção (Canclini, 2012, p. 96).

Pensar a literatura como patrimônio ou, ainda, algumas obras e autores como patrimônios, não parece desprovido de sentido se relembrarmos, ainda que de forma ligeira, todas as estratégias de normatização, regulação e estabilização do campo literário, colocadas em funcionamento desde o momento em que a literatura se institucionalizou, tendo elas, ao mesmo tempo, contribuído fortemente para a efetivação dessa institucionalização. Tal processo, de acordo com o medievalista Paul Zumthor (1987, p. 346, tradução nossa), tem a sua pré-história fundada ainda no século XII, mas encontra sua plena realização a partir do final do século XVIII, quando:

A literatura impregnaria o discurso poético de uma necessidade de regulação, despertaria nele o desejo de uma sistematização de textos, concebida miticamente como advento qualitativo, como universalidade e como humanismo. 
No caso específico em exame, a obra de Borges pode ser tratada como patrimônio seja por sua representatividade para a série literária argentina, o seu lugar na literatura ocidental, as obras que inspirou e as que impossibilitou simplesmente por já existir, uma vez que sua existência e sua leitura e releitura, ao longo dos anos, colaboram para uma normatização, no limite, para a imposição, ainda que indireta, de um conjunto de temas e de modos de tratá-los linguisticamente que nenhum escritor pós-Borges pode ignorar. Pode ser considerada como patrimônio porque "a obra deve ser preservada em sua integridade. [...] $\mathrm{O}$ autor não tem uma obra tangível. É a ideia, ou seja, as palavras. Essa é sua obra, essas são as que devem ser mantidas intactas" (Gelós, s.d., tradução nossa). ${ }^{5}$ A declaração entre aspas, dada pelo advogado de Maria Kodama, viúva e detentora dos direitos autorais de Borges, tem seu contraponto na afirmação de Beatriz Sarlo (2008, p. 21) que argumenta em favor da necessidade de "reler Borges nos dias de hoje, quando a fama tutela sua obra como um aspecto imóvel".

Temos, assim, duas reações distintas ao que chamo de patrimonialização da obra de Borges: ${ }^{6}$ a primeira, que a defende, tem por argumentos o fato de que é necessário proteger a obra do autor, para que ela não seja conspurcada, alterada, para que ela possa sobreviver intacta e íntegra como legado às futuras gerações de leitores; a segunda identifica no processo de patrimonialização um engessamento da obra, que estaria relegada a uma estabilidade incoerente com o próprio processo de leitura que, no limite, é o que garante a vida de qualquer texto, o seu legado; para os tributários dessa posição, ainda que a patrimonialização de uma obra não lhe sequestre o reconhecimento por seu valor estético, este acaba por ser

\footnotetext{
${ }^{5}$ A citação remete a uma declaração de Fernando Soto, advogado de Maria Kodama, viúva de Borges, no processo judicial movido contra Pablo Katchadjian pela publicação do livro El aleph engordado.

${ }^{6}$ Note-se que o conceito de patrimônio desliza entre uma concepção relativa à posse pecuniária (Maria Kodama tem, assim, a posse de um patrimônio que não é simbólico, mas pecuniário, e que vale, de acordo com as últimas negociações de que se tem notícia, alguns milhões de Euros) e uma concepção relativa à valorização simbólica de algo que se deve preservar, um edifício histórico, um monumento, uma cidade, uma dança, uma comida etc. No caso em tela, Kodama usa de seus direitos pecuniários sobre a obra de Borges para conferir, a ela, o que de mais questionável marca o conceito de patrimônio: o de que os objetos, costumes e expressões sob esse rótulo não podem/devem sofrer qualquer modificação a partir dos usos que deles se façam (a esse respeito, ver Canclini, 2012, sobretudo os capítulos 2 e 3).
} 
relegado a um segundo plano, uma vez que - e isso ocorre, sobretudo, na literatura - a elaboração estética da linguagem pressupõe um movimento de elaboração/reelaboração, leitura/releitura, usos, ou, ainda, aquilo que Barthes (1992) identifica em um texto escrevível e que é incompatível com a estabilidade do patrimônio.

Não me interessa, neste artigo, perscrutar quais são os interesses e motivações de Maria Kodama ao investir sempre contra qualquer tentativa de releitura/reescrita/apropriação do texto de Borges ou de sua biografia. ${ }^{7} \mathrm{O}$ que me interessa é entender como o gesto de Katchadjian, ao se apropriar de "El aleph", dispara uma série de reações em cadeia que faz com que a obra de Borges desborde o seu tempo-espaço em direção aos significados que o próprio Borges escritor-crítico/poeta-filósofo - previu como inerentes à literatura e que, ironicamente, vai de encontro ao que Maria Kodama deseja e ao que resulta do processo de patrimonialização. Nas palavras de Beatriz Sarlo (2008, p. 21), Borges é um "escritor que, paradoxalmente, constrói sua originalidade por via da citação, da cópia, da reescrita de textos alheios, porque desde sempre pensa a escrita a partir da leitura e desconfia da representação literária do real."

Ao publicar El aleph engordado, Katchadjian segue cuidadosamente a lição de Borges e isso bastaria para que ele se colocasse, em relação a ele e em relação à autoria literária, de uma maneira muito peculiar, talvez ambígua: ao inserir seu gesto autoral no interior de um texto já existente e da lavra de um autor consagrado, o escritor contemporâneo coloca em xeque a sua própria autoridade de autor, como aquele que dita os significados novos que "nascem" com um novo texto; ao mesmo tempo, assume essa recusa como a sua marca autoral e passa a ser identificado como autor a partir, paradoxalmente, dessa recusa. No que diz respeito a Borges e ao seu conto, ambos são colocados em novos espaços de circulação, aprioristicamente não literários, e passam a ser lidos, muitas vezes, a partir de Katchadjian e desses novos espaços. Ocorre, contudo, que à publicação de El aleph engordado e à

\footnotetext{
${ }^{7}$ María Kodama, antes de processar Pablo Katchadjian, já tinha ido à justiça contra a publicação El hacedor (de Borges), Remake, do escritor espanhol Agustín Fernández Mallo e conseguiu que a editora Alfaguara tirasse os livros de circulação. Também levou à Corte o crítico francês Pierre Assouline, que em um artigo sugeria que ela impedia a publicação de livros de Borges em francês. O biógrafo de Borges, Alejandro Vaccaro, também se tornou alvo de Kodama, ao criticar a forma como ela protegia o espólio do escritor (Gelós, s.d.).
} 
investida judicial de María Kodama contra Pablo Katchadjian seguiram-se episódios e iniciativas que, julgamos, são pertinentes para compreender como se constitui a autoria na contemporaneidade, além de como se configura a própria ideia de literatura no tempo presente.

\section{Apoio a Pablo Katchadjian}

Três anos após a publicação de El aleph engordado, em 2011, Pablo Katchadjian viu-se como réu em processo movido por María Kodama, que o acusa de ter plagiado Borges. A primeira decisão da justiça argentina, em primeira instância, foi pela anulação do processo, contra a qual Kodama apelou, obtendo sucesso: o processo voltou à primeira instância e, em 2015, Katchadjian foi condenado, tendo seus bens bloqueados e correndo o risco de cumprir uma pena de até 8 anos de prisão. ${ }^{8}$ Em maio de 2017, a Câmara de Apelações resolveu, enfim, arquivar o processo, decidindo levar em consideração os muitos testemunhos de estudiosos da literatura, bem como de escritores, amealhados pelo advogado de defesa, que asseveram que o que fez Pablo Katchadjian é um procedimento literário legítimo. A Maria Kodama reserva-se, ainda, o direito de recorrer, o que levaria o caso à Suprema Corte da Argentina, última instância.

O caso reverberou amplamente na mídia, rendendo muitas matérias em jornais e revistas argentinos, brasileiros, espanhóis, franceses e ingleses, e muitas entrevistas que colocaram Katchadjian no centro de um debate bastante acalorado a respeito dos direitos de Kodama sobre a obra de Borges, especificamente, e a respeito da legislação argentina correspondente aos direitos autorais, de modo mais amplo. Na esteira da polêmica, no dia 20 de junho de 2015, um grupo de pessoas criou a página "Apoyo a Pablo Katchadjian" (figura 1), no Facebook, arrebanhando em pouco tempo milhares de seguidores ${ }^{9}$ e dando larga

\footnotetext{
${ }^{8}$ Mais informações podem ser obtidas na Gacetilla de prensa sobre el procesamiento a Pablo Katchadjian, divulgada na página do Facebook "Apoyo a Pablo Katchadjian" e disponível em: https://pt.scribd.com/document/269384356/Gacetilla-de-prensa-sobre-el-procesamiento-aPablo-Katchadjian.

${ }^{9}$ Em uma postagem do dia 20 de junho de 2015 , consta a informação de que 2.000 pessoas curtiram a página em pouco mais de duas horas após a sua criação. Hoje, em 2017, a página conta com 9.021 seguidores.
} 
visibilidade ao processo sofrido pelo escritor e ao próprio escritor - sem mencionar, é claro, a visibilidade dada a Borges e sua obra e à Maria Kodama, ambos já muito populares na Argentina e no mundo, por razões diversas, evidentemente.

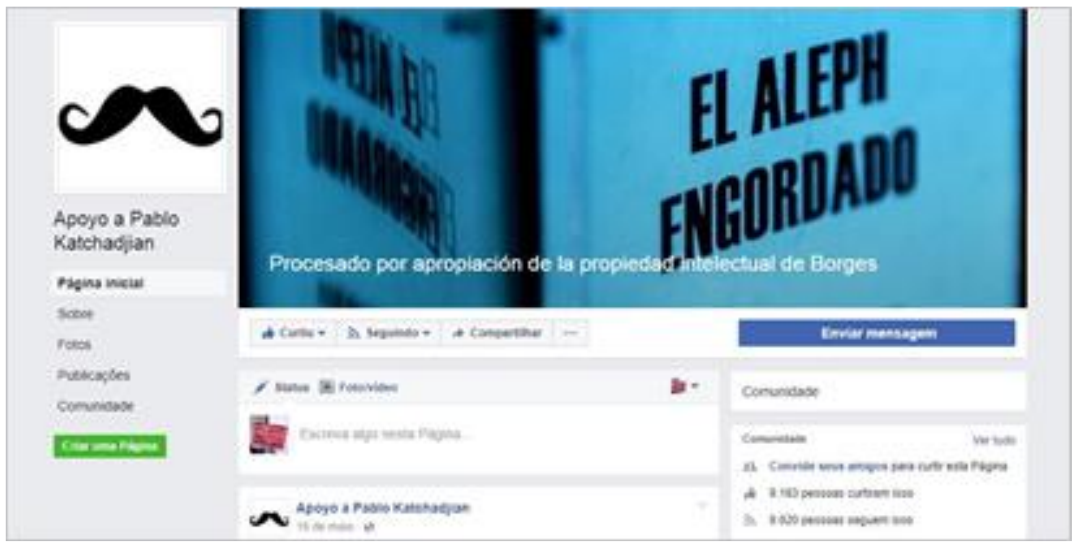

Figura 1 - Fanpage de Apoio a Pablo Kachadjian no Facebook

Na postagem que poderia ser identificada como a petição de princípios que motivaram a criação da página, consta uma declaração de autoria de Juan Laxagueborde ${ }^{10}$ (figura 2).

Os comentários que se seguem a essa postagem inaugural - as anteriores são atualizações de capa - oscilam entre o inconformismo com o que se identifica como um desconhecimento da obra de Borges, por parte de Kodama, e uma primeira categorização da relação entre as obras deste e a de Katchadjian: influência. É curioso notar, ainda, que alguns dos comentários evidenciam a motivação de fazer circular, no formato PDF, El aleph engordado, cuja tiragem inicial, como se viu, fora exígua, de cerca de 300 exemplares. É quase lógico que, nesse momento de criação da página, a esmagadora maioria desses seguidores não tinha tido acesso ao livro de Katchadjian ainda, o que justifica, outrossim, a recomendação, feita em tom de chamamento, de convocatória, para que se leia, a partir de então, a sua obra. É também

\footnotetext{
${ }^{10}$ A informação é dada em um dos comentários da postagem.
} 
nos comentários dessa postagem inaugural que um dos seguidores propõe que "engordemos a Borges en las redes".

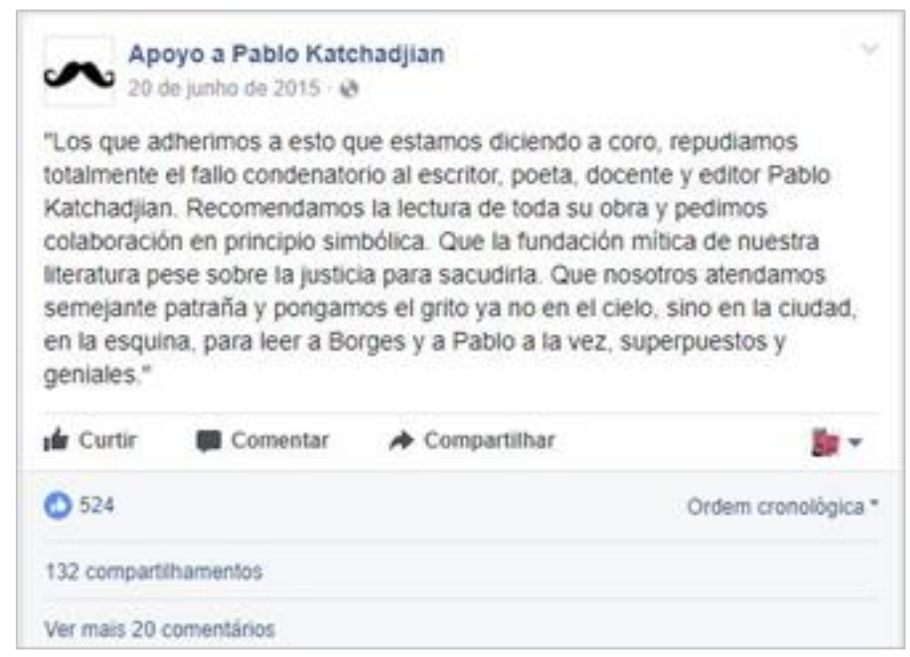

Figura 2 - Postagem de criação da fanpage.

No dia 22 de junho, uma postagem sugere que se crie uma página em que se possa "citar" o texto de Borges no limite do que permite a legislação argentina de direitos autorais, que reza que qualquer texto que retome outro, seja para qual finalidade for, deve limitar-se à reprodução de até 1.000 palavras..$^{11}$ É em comentário a essa postagem que se apresenta, então, o site "\#YoBorges",12 que, no dia 24 de junho, torna-se o tema principal de uma outra postagem (figura 3).

O site "\#YoBorges" fora criado em 2014, por Diego de la Fuente e, a princípio, não tinha nenhuma relação com o caso Pablo Katchadjian, ${ }^{13}$ tendo sido, de certa forma, apropriada pelo movimento de apoio ao escritor. A postagem em que Diego apresenta a página, em 2014, teve 11

\footnotetext{
${ }^{11}$ Uma postagem subsequente sugere que cada um dos participantes do grupo "arme" um texto com 999 palavras de Borges e o envie a um endereço de e-mail. Planejava-se organizar um texto único que se publicaria, posteriormente. Não se sabe se a empreitada foi levada a cabo.

${ }^{12}$ Disponível em: <http://www.yoborges.com.ar>.

${ }^{13}$ Inicialmente, "Yo Borges" fora publicada no blog pessoal de Diego de la Fuente, disponível em: <https://fumado.wordpress.com/>.
} 
compartilhamentos; em contrapartida, a postagem publicada na página de apoio a Katchadjian teve 396 compartilhamentos, evidenciando, dessa forma, que a apropriação de "\#YoBorges" pela página de apoio ampliou consideravelmente sua circulação.

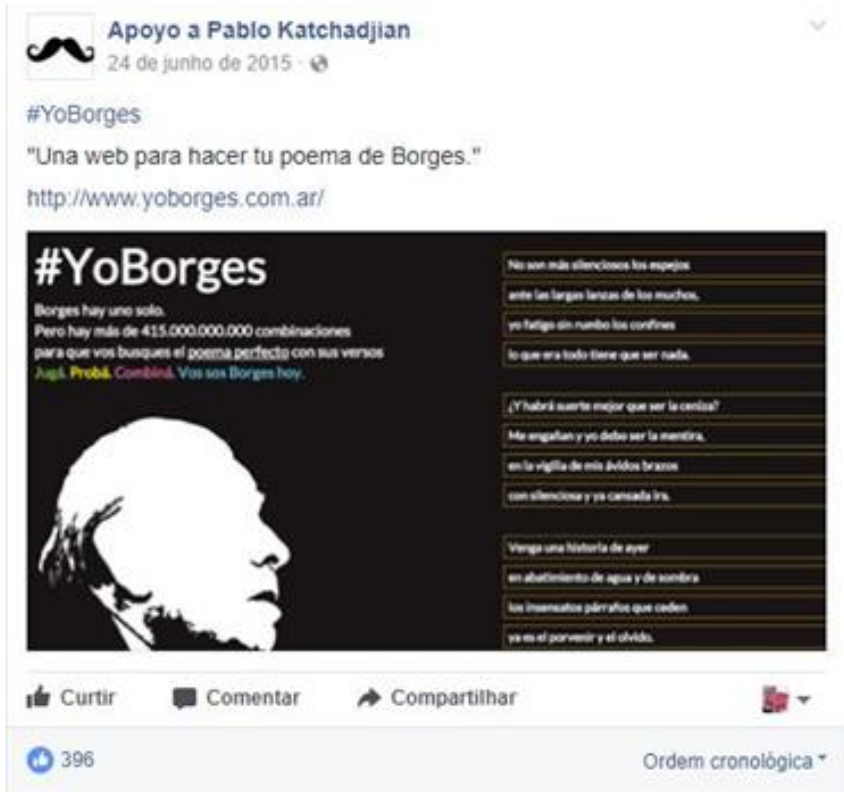

Figura 3 - Postagem de divulgação do site \#YoBorges.

Conforme se lê na descrição do site, "\#YoBorges" propõe-se a "por meio de textos borgianos e combinatória, [...] provar que o poema perfeito de Borges foi escrito por ele e está oculto entre todos os seus versos" (tradução nossa). Para tanto, organiza-se, desde a página inicial, como uma espécie de jogo em que o leitor pode, enfim, construir o seu próprio poema a partir da combinação de versos de autoria de Borges e, caso goste do resultado, compartilhar nas redes sociais.

A primeira página do site dá acesso, ainda, a partir de hyperlinks, a uma página cujo objetivo é expor o que se denomina por "resumen y hipótesis" e "antecedentes" da proposta. Um pequeno texto se segue, salpicado por vários links que dão acesso a outros sites e páginas (Wikipedia, livros teórico-críticos, sites com textos críticos de Borges). O objetivo do texto e dos links parece ser criar um percurso de leitura 
que evidencie de que maneira, ao buscar o "poema perfeito" (esse que o leitor tem a chance de descobrir ao manipular os versos de Borges), o escritor acabou por expor a sua própria concepção de literatura - ou, pelo menos aquela concepção de literatura que melhor se ajusta aos objetivos de justificar um projeto como o do site que examinamos. Vem do conto "Tlön, Uqbar, Orbis, Tertius" (Borges, 1974, p. 439, tradução nossa), a citação, acessada por meio de um link da Wikipedia, que se coloca nessa página: "Nos hábitos literários, também é onipotente a ideia de um sujeito único. É raro que os libros sejam assinados. Não existe o conceito de plágio: estabeleceu-se que todas as obras são obra de um só autor, que é atemporal e anónimo."

A breve descrição que fiz do site torna patente que o motivo pelo qual a página no Facebook "Apoyo a Pablo Katchadjian" apropriou-se do site "\#YoBorges" deve-se ao vínculo entre a faceta da obra de Borges a que interessava remeter e que é evidenciada pelo site - a do Borges afeito às reapropriações e citações. Tal vínculo era por demais pertinente para ser ignorado. Além disso, a proposta de Diego de la Fuente para o site era, em última instância, manipular o texto de Borges e incentivar que outros fizessem o mesmo, promovendo, assim, um deslizamento entre as entidades autor-leitor, ou seja, algo muito próximo ao que fez Katchadjian.

Outro aspecto a ser considerado diz respeito à maneira como o site "\#YoBorges" coloca em ampla circulação - muito mais ampla do que os 300 exemplares de El aleph engordado - uma determinada interpretação da obra literária e crítica de Borges que não é a única, mas que provavelmente é a mais popular, aquela que o aproxima das perspectivas pós-estruturalistas acerca dos conceitos de autoria, de obra e de originalidade, como mencionamos na primeira seção deste ensaio. Há que se mencionar, também, que a página do Facebook, "Apoyo a Pablo Katchadjian" coloca em circulação, sobretudo nos comentários às postagens, a mesma compreensão desses conceitos.

A relação que se estabeleceu, assim, entre a obra de Borges, El aleph engordado, de Pablo Katchadjian, a página do Facebook "Apoyo a Pablo Katchadjian" e a página idealizada por Diego de la Fuente, \#YoBorges, pode ser compreendida como circuitos de circulação do literário que só se tornaram possíveis graças ao contexto digital e, mais especificamente, à Web 2.0. Tal circuito faz com que cada um 
desses elementos que o compõem tenha seus significados primeiros alterados no momento em que passam a existir em rede.

A página \#YoBorges talvez ofereça o caso em que tal hipótese possa ser aferida com maior facilidade: sua "motivação" inicial, como os textos que a compõem fazem notar, era a de propor a descoberta do poema perfeito, tal qual o entendia Borges, a partir da manipulação da própria obra de Borges, em uma espécie de jogo que o escritor argentino sempre propôs a seus leitores, mas que, graças à concepção de Diego de la Fuente, formalizou-se em plataforma digital por meio de estratégias combinatórias; tal proposta, embora embase a concepção da página, foi eclipsada pela apropriação que dela se fez, ou seja, quando foi inserida no circuito das manifestações em apoio ao autor de El aleph engordado. A partir dessa apropriação, desse uso, como prefere Canclini (2012), \#YoBorges torna-se um convite para que todos se arrisquem, como fez Pablo Katchadjian, a manipular o texto de Borges, a construir uma autoria a partir de Borges e, por que não, a provocar Maria Kodama.

\section{Considerações finais}

O percurso que propus, neste artigo, é uma tentativa de enfrentar criticamente não apenas o texto literário contemporâneo mas também seus processos de circulação, de constituição de sua autoria e de legitimação do seu valor. Um texto caracterizado como literário cumpriu um longo percurso em que se articularam suas opções temático-formais, seu diálogo com a tradição, sua circulação em ambientes simbólicos (academia, publicações especializadas, etc.) e geográficos (a sua posição em determinada estante nas livrarias, por exemplo) específicos, a sua formalização material (como a escolha da capa e das fontes), a performance de seu autor, o marketing de seu lançamento, só para citar alguns aspectos e não incorrer na vertigem das listas borgianas. Tal percurso não se conclui no momento em que o texto literário passa a ser assim caracterizado, uma vez que ele continua em circulação, sendo lido, relido, reeditado, estudado, apropriado por outros textos e/ou por outras manifestações artísticas ou não artísticas, com maior ou menor facilidade, a depender de seu alcance simbólico, de sua disponibilidade material, e, felizmente, à revelia de Marias e Kodamas. 
A partir desse pressuposto e diante das relações que se estabelecem, e que procurei descrever, entre os textos de Borges, Katchadjian, e a página "Apoyo a Pablo Katchadjian" e o site \#YoBorges, é difícil empregar as categorias críticas que convencionalmente são usadas para analisar as complexas redes de apropriações e diálogos entre textos, tão recorrentes na literatura. Isso porque, se o pós-estruturalismo questionou a origem e a originalidade, rasurando a autoridade do autor e do texto "primeiro" - algo que a ficção pós-modernista explorou e explora como um dos seus traços recorrentes -, o contexto digital e a cibercultura levam ao paroxismo tais questionamentos e rasuras, já que artistas plásticos, músicos, escritores e leitores adquirem, cada vez mais, possibilidades técnicas e posturas ideológicas que fazem com que o compartilhamento, os recortes, as montagens não sejam mais - talvez não apenas procedimentos de rebeldia estética, mas o ramerrão da produção cultural da atualidade. Pablo Katchadjian intui isso, ao afirmar que “para mim, poder fazer livros assim é uma conquista de certa liberdade literária. Há muitos textos dando voltas por aí. Poder usálos confere um sentido a... muitas coisas" (s.d., tradução nossa).

El aleph engordado não usa apenas o conto "El aleph" em sua construção. Como espero ter demonstrado, o texto de Katchadjian usa também o mise en forme borgiano, já que busca nos traços autorais de Borges - pelo menos os mais discutidos pela crítica - a receita para sua constituição. Além disso, usa a patrimonialização de Borges (no sentido simbólico, mas também pecuniário) como matéria-prima para um libelo contra as tentativas de engessamento e de imobilidade dos textos que, no contexto digital estão "dando voltas por aí". Fazendo isso, Katchadjian ${ }^{14}$ constitui-se como autor, não só porque escreve, mas porque é reconhecido como autor, ${ }^{15}$ talvez antes mesmo de ter sua obra lida, levando-se em consideração

\footnotetext{
${ }^{14}$ Com isso não quero dizer que Katchadjian tenha deliberadamente planejado se promover às custas de Borges, o que, de qualquer forma, é uma observação totalmente irrelevante (ainda que possa ter fundamento, não há como saber) levando-se em consideração os traços da cibercultura que mencionamos anteriormente.

${ }^{15}$ Uma rápida pesquisa, usando o Google como ferramenta, revela a existência de quatro resenhas/ensaios a respeito da obra de Pablo Katchadjian, antes de Maria Kodama levá-lo a juízo pela publicação de El aleph engordado. Depois de 2015, ano em que Kodama recorre da absolvição em primeira instância do escritor, somam-se mais de duzentas menções, entre notícias, entrevistas, resenhas e ensaios.
} 
a pouca circulação que seus livros alcançavam anteriormente à sua condenação pela publicação de El aleph engordado.

"\#YoBorges" também faz uso de Borges, usando, assim como Katchadjian, não só as palavras do mestre argentino como também sua mise en forme, desta vez atualizada em linguagem computacional, em um programa de matriz combinatória. E também faz uso de El aleph engordado, vinculando-se - como vimos, espontaneamente - à causa de apoio à Katchadjian, inaugurada em página homônima no Facebook.

Embora difícil de prever e, mais ainda, de comprovar, não é absurdo conceber que o círculo se fecha na volta a Borges, quando leitores e internautas de hoje e do futuro venham a conhecer a sua obra por meio do "caso Katchadjian", dos percursos e percalços de um texto e de um autor no contexto da contemporaneidade digital.

\section{Referências}

AIRA, César (2009-2010). El tiempo y el lugar de la literatura: acerca de $E l$ Martín Fierro ordenado alfabéticamente y El Aleph engordado, de Pablo Katchadjian. Otra Parte: revista de letras y artes, Buenos Aires, n. 19. On-line. Disponível em: <https://bit.ly/2ManMKx>. Acesso em: 4 ago. 2017.

APOYO a Pablo Katchadjian. Página do Facebook. On-line. Disponível em: $<$ https://www.facebook.com/ Apoyo-a-Pablo-Katchadjian-

1599418800322990>. Acesso em: 4 ago. 2017.

BARTHES, Roland (2004). A morte do autor. In: BARTHES, Roland. O rumor da língua. Tradução de Maria Laranjeira. São Paulo: Martins Fontes. p. 57-64.

BARTHES, Roland. (1992). S/Z. Tradução de Lea Neves. Rio de Janeiro: Nova Fronteira.

BORGES, Jorge Luis (1972). Ficções. Tradução de Carlos Nejar. São Paulo: Abril.

BORGES, Jorge Luis (1974). Obra completa: 1923-1972. Buenos Aires: Emecê.

CANCLINI, Néstor García (2012). A sociedade sem relato. Tradução de Maria Paula Gurgel Ribeiro. São Paulo: EDUSP.

CHARTIER, Roger (2012). O que é um autor? Revisão de uma genealogia. Tradução de Luzmara C. Ferreira. São Carlos: Editora da UFSCar.

FOUCAULT, Michel (1992). O que é um autor? Tradução de António Fernando Cascais e Eduardo Cordeiro. Lisboa: Vega. 
FUENTE, Diego de la (s.d.). \#YoBorges. Website. On-line. Disponível em: <http://www.yoborges.com.ar/>. Acesso em: 4 ago. 2017.

GELÓS, Natalia (s.d.). \#injusticiapoética. Kodama vs. El mundillo literário. Revista Anfibia, Buenos Aires. On-line. Disponível em: <https:/ / bit.ly/2rnavzp>. Acesso em: 4 ago. 2017.

KATCHADJIAN, Pablo (s.d.). Entrevista a Juan Terranova. La tercera opinión, [S.l.], n. 4. On-line. Disponível em: <https://goo.gl/ZpZ6GC>. Acesso em: 4 ago. 2017.

NUEVO fallo. Sobreseyeron (otra vez) al escritor que "engordo" un cuento de Jorge Luis Borges. Clarín, Cultura, 16 maio 2017. On-line. Disponível em: <https:/ /clar.in/2P2jv9S>. Acesso em: 4 ago. 2017.

NUNBERG, Geoffrey (1993). The places of books in the age of electronic reproduction. Representations, Berkeley, n. 42, p. 13-37.

REIS, Vilto (s.d.). Pablo Katchadjian, um escritor da vanguarda literária argentina. Homo Literatus, [S.l.], [s.d.]. On-line. Disponível em: <https:/ / bit.ly/2ntTDau>. Acesso em: 4 ago. 2017.

SARLO, Beatriz (2008). Jorge Luis Borges: um escritor na periferia. Tradução de Samuel Titan Jr. São Paulo: Iluminuras.

ZUMTHOR, Paul (1987). La letra y la voz. Tradução de Julián Presa. Madri: Cátedra.

Recebido em 7 de setembro de 2017.

Aprovado em 16 de abril de 2018.

\section{resumo/abstract/resumen}

\section{Textos que dão voltas por aí: Borges, Katchadjian, obra e autoria na literatura contemporânea}

Rejane Cristina Rocha

Este artigo propõe a discussão de um caso, que teve início com a publicação de El aleph engordado, de Pablo Katchadjian, posteriormente levado a juízo por Maria Kodama, viúva de Jorge Luis Borges e detentora dos seus direitos autorais, e que ganhou repercussão com a criação da página no Facebook "Apoyo a Pablo Katchadjian" e com a vinculação do site \#JoBorges ao movimento de defesa de Katchadjian. A maneira como a apropriação do texto de Borges por Katchadjian bem como a forma como a obra de ambos os 
escritores passam a circular em rede são discutidas a partir de pressupostos relacionados à circulação do literário no contexto digital, para refletir de que maneira podem ser compreendidos, na contemporaneidade, os conceitos de autoria, autor e obra.

Palavras-chave: autoria, obra, El aleph engordado.

Texts that go around: Borges, Katchadjian, work and authorship in contemporary literature

Rejane Cristina Rocha

This article discusses a case that began with the publishing of El Aleph engordado, by Pablo Katchadjian. The author was sued by Maria Kodama, the widow of Jorge Luis Borges and owner of his copyrights. The case then gained notoriety with the creation of the Facebook page "Apoyo a Pablo Katchadjian" and with the metadata tag \#JoBorges, used in the movement in Katchadjian's defense. The article discusses the appropriation of Borges' text by Katchadjian, as well as the way that both authors' work begin to circulate in digital platforms. Finally, taking into account the circulation of literary material in digital contexts, this essay reflects on the way the concept of authorship, author and work can be understood in the present context.

Keywords: authorship, literary work, El Aleph engordado.

\section{Textos que dan vueltas por ahí: Borges, Katchadjian, obra y autoría en la literatura contemporánea}

Rejane Cristina Rocha

Este artículo propone una discusión de un caso que tuvo su comienzo con la publicación de El Aleph engordado, de Pablo Katchadjian, posteriormente llevado a juicio por Maria Kodama, viuda de Jorge Luis Borges y poseedora de los sus derechos de autor, y que tuvo repercusión con la creación de la página en Facebook "Apoyo a Pablo Katchadjian" y con la vinculación del sitio web \#YoBorges al movimiento de defensa de Katchadjian. La manera como la apropriación del texto de Borges, por Katchadjian, como también la forma como la obra de ambos escritores pasan a circular en redes son discutidas a partir de presuposiones relacionadas a la circulación de lo literario en el contexto digital, para reflexionar respecto al modo como pueden ser comprendidos, en la contemporaneidad, los conceptos de autoría, autor y obra.

Palabras-clave: autoría, obra, El Aleph engordado. 